\title{
Patient Blood Management: It Is Time to Streamline Targeted Therapy Options
}

\author{
Peter Schlenke ${ }^{a}$ Donat R. Spahn ${ }^{b}$ \\ a Department of Blood Group Serology and Transfusion Medicine, Medical University Graz, Graz, Austria; \\ ${ }^{\mathrm{b}}$ Institute of Anesthesiology, University and University Hospital of Zurich, Zurich, Switzerland
}

By searching in the U.S. National Library of Medicine in March 2015, surprisingly less than 100 articles titles contain the term 'patient blood management'. Nevertheless, patient blood management has been received much attention worldwide in recent years, resulting in hospital-based or national campaigns to educate physicians and nurses in the three-pillar concept of patient blood management [1]. Like many other medical procedures, patient blood management aims at improving the patients' outcome and safety. By then, everything seems to be business as usual, and obviously one might not imagine that the topic is highly charged both politically and emotionally. All stakeholders in healthcare need to overcome the ongoing controversy about the benefit-risk ratio of blood transfusions.

Patient blood management is defined as evidence-based multidisciplinary approach to preoperatively screen and treat patients for anemia, to minimize intraoperative blood loss by elaborating meticulous surgical techniques, individualized goal-directed coagulation management and cell salvage, and finally to harness the patient's physiological capacity for compensation of low hemoglobin levels prior to application of allogeneic blood transfusions $[1,2]$. Compared with initiatives for optimal blood use with their motto 'transfusion of the right unit of blood to the right patient at the right time', it is obvious that patient blood management is a broader concept covering many more issues.

The evidence-based medicine approaches are well accepted by the vast majority of scientists and physicians as it facilitates the individual decision making for diagnosis, investigation, and/or therapy by emphasizing different levels of evidence from well-designed and well-conducted randomized clinical trials, systematic reviews, and meta-analyses. Patient blood management is strictly based on the principles of evidence-based medicine. Therefore, it promotes turning away from purely empirical knowledge and fosters the conduction of further clinical trials with special patient subsets, e.g. patients with septic shock [3] and traumatic brain injury [4], The results of these two studies are in line with the overall statement of a recently published Cochrane review that has evaluated the data of 19 randomized clinical trials with a total of 6,264 patients involved [5].

The multidisciplinary approach describes teamwork of multiple disciplines to 'redefine problems outside of normal boundaries and reach solutions based on a new understanding of complex situations' (http://en.wikipedia.org/wiki/Multidisciplinary_approach). This definition of the free encyclopedia Wikipedia perfectly fits with the challenges of patient blood management. To increase the overall effectiveness specialists of as many disciplines as possible need participating in patient blood management programs. This includes anesthesiologists, surgeons of different specialties, intensive care physicians as well as specialists in transfusion medicine and hemostaseology. Furthermore, these programs need to be expanded into nonsurgical patients such as those of internal medicine, oncology, and pediatrics.

Obviously, for successfully implementing patient blood management bedside physicians are the primary target persons in order to avoid unnecessary allogeneic blood transfusions or their inappropriate application. They should be particularly educated in updated transfusion policies and alternative interventions such as the preoperative treatment of anemia by intravenous iron and/or erythropoietin. Anemia is an independent risk factor for higher morbidity and mortality $[6,7]$. Therefore, patient blood management does not focus simply on the adherence of transfusion triggers for specific patient cohorts, such as a threshold of 7 or $8 \mathrm{~g} / \mathrm{dl}$ [8], but aims at the screening, monitoring, and treatment any kind of mild to severe anemia prior to surgical intervention and/or during nonsurgical treatments if indicated [2].

Considering the results obtained from a variety of randomized clinical trials, it is time to streamline targeted therapy options either to correct iron deficiency anemia in patients who undergo surgery or to identify patients who are at risk for complications such as myocardial and cerebral ischemia due to severe anemia and thus will benefit from allogeneic blood transfusions.

\section{KARGER}

Fax +497614520714 (c) 2015 S. Karger GmbH, Freiburg

$1660-3796 / 15 / 0422-0072 \$ 39.50 / 0$
Prof. Dr. Peter Schlenke

Department of Blood Group Serology and Transfusion Medicine Medical University Graz

Auenbruggerplatz 48, $8036 \mathrm{Graz}$, Austria

Peter.Schlenke@klinikum-graz.at 
Blood donation establishments and specialists in the field of transfusion medicine should be aware that the paradigm shift to a more restrictive use of allogeneic blood or its strict avoidance, if suitable alternatives are available, is already underway in health research and healthcare nowadays [2]. We do well to strengthen our professional ethics to cure patients or to ameliorate illnesses and injuries to our best knowledge. So, voluntary blood donations and their state-of-the-art use is rather an issue of quality than of quantity.

\section{References}

1 Williamson LM, Devine DV: Challenges in the management of the blood supply. Lancet 2013;381:1866-1875.

2 Spahn DR, Goodnough LT: Alternatives to blood transfusion. Lancet 2013;381:1855-1865.

3 Holst LB, Haase N, Wetterslev J, et al: Lower versus higher hemoglobin threshold for transfusion in septic shock. N Engl J Med 2014;371:1381-1391.

4 Robertson CS, Hannay HJ, Yamal JM, et al: Effect of erythropoietin and transfusion threshold on neurological recovery after traumatic brain injury: a randomized clinical trial. JAMA 2014;312:36-47.
Carson JL, Carless PA, Hébert PC: Transfusion thresholds and other strategies for guiding allogeneic red blood cell transfusion. Cochrane Database Syst Rev 2012;4:CD002042.

6 Musallam KM, Tamim HM, Richards T, Spahn DR, Rosendaal FR, Habbal A, Khreiss M, Dahdaleh FS, Khavandi K, Sfeir PM, et al: Preoperative anaemia and postoperative outcomes in non-cardiac surgery: a retrospective cohort study. Lancet 2011;378:1396-1407.
Baron DM, Hochrieser H, Posch M, Metnitz B, Rhodes A, Moreno RP, Pearse RM, Metnitz P, European Surgical Outcomes Study Group for the Trials Groups of the European Society of Intensive Care Medicine, the European Society of Anaesthesiology: Preoperative anaemia is associated with poor clinical outcome in non-cardiac surgery patients. Br J Anaesth 2014;113:416-423.

8 Hébert PC, Carson JL: Transfusion threshold of $7 \mathrm{~g}$ per deciliter - the new normal. N Engl J Med 2014;371 1459-1461. 